\title{
A IMPORTÂNCIA DA HISTÓRIA E DA CULTURA NAS LEITURAS DA NATUREZA*
}

Leandro Belinaso Guimarães**

\section{RESUMO}

O presente artigo apresenta brevemente alguns dos modos pelos quais a natureza vem sendo historicamente significada na cultura. Para tanto, o texto focaliza, em sua primeira parte, dois momentos históricos distintos, mostrando algumas das disputas em torno dos significados de natureza que se travaram nas sociedades daqueles períodos. Em sua segunda parte, o ensaio foca mais detidamente a emergência dos movimentos ecológicos contestatórios dos anos 1970 e, ainda, o posterior surgimento de um campo contestado de saberes e práticas: a educação ambiental. Em todos estes diferentes momentos históricos, a centralidade da cultura é destacada em relação aos modos como se lê a natureza.

Palavras-chave: Estudos culturais. Educação ambiental. História ambiental. Movimentos ecológicos.

Os modos como enxergamos e nos relacionamos com a natureza são frutos do momento histórico em que vivemos. ${ }^{1}$ Podemos compreender, portanto, que em diferentes tempos e espaços são configuradas inúmeras formas de vermos e lermos a natureza, e de estabelecermos relações com ela. Muitas vezes, não percebemos que os nossos atos, as maneiras de narrar acontecimentos, os modos de vermos a nós mesmos e aos outros e, ainda, nossas escolhas cotidianas, tudo isso, são negociações que vamos estabelecendo diariamente com os significados que nos interpelam através da cultura. Somente compartilhando os significados que circulam pelas sociedades, seja através das relações de amizade e vizinhança que estabelecemos, dos programas a que assistimos na

\footnotetext{
* Artigo recebido em 14/02/2008 e aprovado em 3/06/2008.

** Doutor em Educação (UFRGS), professor do Programa de Pós-Graduação em Educação da Universidade Federal de Santa Catarina. E-mail: lebelinaso@uol.com.br
} 
televisão, dos cursos que fazemos, das revistas e livros que lemos, das notícias que escutamos no rádio, seja através dessas variadas relações que constituímos cotidianamente é que vamos aprendendo a tomar algumas decisões, a ver e a ler de determinada forma as coisas do mundo e a estabelecer relações com os outros e com a natureza. Com isso, vemos que é na cultura, nesse espaço de circulação e de compartilhamento de significados, que vamos aprendendo a lidar com a natureza e, também, vamos estabelecendo nosso lugar no mundo, ou seja, sabendo quem nós nos tornamos dia a dia.

Essa nossa inserção na cultura, no momento histórico em que vivemos, nos faz ver e estabelecer relações com a natureza de determinadas formas. Nesta direção, podemos nos perguntar: há uma única maneira de narrar, ler e ver a natureza?

Se assumirmos a importância da história e da cultura nos modos como nos relacionamos com a natureza, responderemos negativamente a esta indagação e defenderemos, como já nos alertou Wortmann (2001), que há uma multiplicidade de representações de natureza circulantes na cultura, implicando em modos diferenciais de estabelecimento de relações dos humanos com ela. Contudo, precisamos estar atentos para não pensarmos que cada indivíduo, solitariamente através de sua consciência, seja capaz de construir sua própria idéia de natureza. Tais idéias são definidas cultural e historicamente.

Uma outra questão que precisamos considerar é que, em um mesmo momento histórico, diferentes representações culturais de natureza circulam pelas sociedades e, muitas vezes, contestam-se mutuamente. Sem maiores detalhamentos, podemos ver explicitamente essa multiplicidade de significações, por exemplo, em torno da questão dos produtos transgênicos. Há diferentes modos de significá-los e, tais maneiras, dizem respeito aos diversos interesses em jogo nessa disputa.

Em resumo, sabemos que há uma multiplicidade de formas de ver, ler, narrar e se relacionar com a natureza. Essas diferenças são construídas histórica e culturalmente. E, mais, não há uma única forma, também, quando focamos um mesmo período ou uma aparente mesma conformação cultural. Vejamos um pouco mais sobre isso, por meio de um exemplo específico.

Os imigrantes alemães que chegaram ao Sul do Brasil no século XIX foram alocados em regiões de mata nativa. As práticas de desmatamento foram vistas amplamente como necessárias para garantir o 
desenvolvimento e o progresso da região, na qual os imigrantes foram assentados. Já naquela época, nos mostram Wortmann e Braun (2003), tais práticas de desmatamento, associadas, inclusive, com as queimadas, foram também vistas como problemáticas, pois produziam o esgotamento do solo, prejudicando o cultivo agrícola. Em certa medida, aquilo que era solução para muitos passou também a ser visto como um problema para alguns. Nesse sentido, podemos ver que, em uma mesma época e região, houve divergências relativas aos modos de se estabelecer relações entre os imigrantes alemães e as áreas florestais.

De acordo com os códigos culturais que são compartilhados pelos sujeitos, algo que é visto como uma "solução" para alguns pode também ser compreendido como um "problema" para outros. Tal antagonismo, aqui exemplificado de forma simplificada (importante pensar que, possivelmente, são vários os significados em jogo sobre uma mesma temática ou questão), não se refere apenas a uma questão de consciência individual. Lembramos que as posições que tomamos e os entendimentos que apresentamos são frutos dos códigos sociais que compartilhamos.

Vamos ver, agora, um pouco mais sobre essa multiplicidade de formas de ler a natureza. Faremos isso a partir de dois diferentes momentos da história ocidental, mas que dizem respeito aos modos como a América Latina (o chamado, antigamente, Novo Mundo) foi sendo narrada desde a chegada dos europeus, sobretudo os espanhóis e os portugueses da Península Ibérica, à época das grandes navegações.

\section{As GRANDES NAVEGaÇÕES E AS NARRATIVAS SOBRE o Novo Mundo}

Pensamos ser importante iniciar este tópico explicitando que consideramos a noção de "Novo Mundo" como um espaço simbólico e conceitual e não, simplesmente, físico e territorial. Essa denominação referia-se ao modo como os europeus, especialmente da Península Ibérica (Portugal e Espanha), passaram a narrar as "novas" terras, hoje chamadas de continente americano, conquistadas após longas e dificultosas viagens pelos oceanos, sobretudo nos séculos XV e XVI. Antes de o Novo Mundo destacar-se como uma noção identificadora de um território singular, as "Índias", como salienta Leite (1996), foi um nome genérico estendido para significar todo espaço considerado bizarro, estranho, misterioso, exótico, ou seja, todas aquelas terras que não estavam incorporadas ao Velho Mundo europeu. 
Tal denominação "Novo Mundo", identificando pela primeira vez um continente separado da Ásia - no qual estavam localizadas, conforme os discursos da época, as "Índias" -, foi cunhada pelo navegador italiano Américo Vespúcio, em publicação datada de 1503, intitulada Mundus novus. Posteriormente, o viajante seria, inclusive, homenageado ao batizar-se com seu nome o continente americano. Embora considerada apócrifa, tal obra repercutiu amplamente como um dos maiores sucessos de leitura na Europa do século XVI. Através dela, podemos dizer que se disseminou pela Europa a associação do Novo Mundo com os temas paradisíacos. Vejamos um pequeno trecho da narrativa de Vespúcio, no qual podemos ler esta vinculação. Nas palavras do autor:

Esta terra é muito amena; cheia de inúmeras árvores verdes, e muito grandes, e nunca perdem folha, e todas têm odores suavíssimos, e aromáticos, e produzem inúmeras frutas, e muitas delas boas ao gosto e saudáveis ao Corpo, e os campos produzem muita erva, e flores, e raízes muito suaves, e boas, que umas vezes me maravilhava do odor suave das ervas, e das flores, e do sabor dessas frutas, e raízes, tanto que em mim pensava estar perto do Paraíso terrestre. (Vespúcio apud Zilberman, 1994, p. 15)

Destacamos que o Brasil, como parte do Novo Mundo, compartilhou desse universo simbólico, sendo que a natureza será posteriormente consagrada, nos salienta Zilberman (1994), como síntese de suas virtudes mais essenciais. Parece-nos interessante marcar ainda que a vinculação do Novo Mundo ao tema do Paraíso terrestre foi possível tanto em razão de concepções bíblicas como também de idealizações medievais pagãs. Uma conjunção dessas narrativas permitiu que tal associação emergisse nas narrativas sobre a América (como é chamada atualmente).

Interessante constatar que a noção de trópicos constituiu-se também como um outro modo de nomear aquelas terras longínquas do Novo Mundo. Os trópicos converteram-se, desde os tempos das navegações européias dos séculos XV e XVI, em uma maneira ocidental de definir simbolicamente algo como culturalmente alheio à Europa. A noção de trópico residiria em uma profunda ambivalência, pois, como nos diz David Arnold (2001), em parte "sonho fascinante de opulência e exuberância - ilhas paradisíacas em mares resplandecentes -, os trópicos significaram ao mesmo tempo um mundo estranho de crueldade e enfermidade, de opressão e escravidão" (p. 130). O autor também nos mostra que os primeiros cronistas europeus e brancos que escrituraram a América a 
constituíram com a imagem do Éden terrestre. A idéia dos trópicos como ilhas paradisíacas, formosas e pródigas, se contrapunha à monotonia humanizada da Europa. Porém, seria equivocado pensarmos que só houve uma imagem paradisíaca sobre os trópicos, pois tais imagens conviveram ao mesmo tempo com outras de terror, perigo e repugnância.

Uma ampla literatura de viagem escriturada na época das grandes navegações marcou a América tropical como um território de natureza exuberante, como uma região maravilhosa e encantada, na qual residiria, ou ao menos pareceria residir, o Paraíso Terrestre, com seus campos fertilíssimos, com um clima de perene primavera, no qual encontraríamos a Fonte da Juventude e a árvore do Bem e do Mal (LeITE, 1996). Porém, como já salientamos antes, em uma mesma época histórica e também em uma determinada circunstância, a natureza tropical, por exemplo, foi lida e vista de formas diferenciais. Vejamos melhor tal consideração que temos insistentemente marcado.

Em uma importante obra de interpretação do Brasil chamada Visão do Paraíso, Sérgio Buarque de Holanda (1996) também nos mostra que foi sendo difundida na Europa, desde a época dos descobrimentos marítimos dos séculos XV e XVI, a visão dos trópicos como o Éden terrestre. $\mathrm{O}$ estudioso destaca que os teólogos da Idade Média não representavam o Paraíso terrestre como um mundo inatingível e incorpóreo, mas, embora recôndito, como plenamente acessível. Tal pressuposto conformou, ou seja, instituiu as imagens e as narrativas dos navegadores daqueles tempos. O autor ressalta que uma imagem contrária a essa "fantasia" também esteve presente naqueles séculos. Nas palavras do autor: "não serão apenas primores e deleites o que se há de oferecer aqui ao descobridor [Cristóvão Colombo]. Aos poucos, nesse mágico cenário, começa ele a entrever espantos e perigos" (p. 16). Todavia, salienta também que tal negação nunca ocupou um espaço tão amplo e extremado nos discursos da época como o da idealização paradisíaca do Novo Mundo.

Uma fauna de seres fantásticos (sereias, amazonas, cinocéfalos, homens caudatos), que imbuíam de medos e arrepios os viajantes, foi vista não como marcando um lugar infernal, uma negação da visão paradisíaca dos trópicos, mas, pelo contrário, reforçando-a, pois tal fauna foi concebida como feita pela vontade divina, ou seja, como constituinte do próprio jardim do Éden.

Em resumo, a imagem do Novo Mundo como o Éden terrestre cristalizou-se e consolidou-se com força através das narrativas de viagem 
na época das grandes navegações, sendo que as negações a essa imagem, embora presentes em algumas narrativas da época, nunca mereceram grande destaque. Foram apenas no movimento ilustrado do século XVIII que tais visões negativas edificaram-se com maior amplitude e disseminação, buscando romper com a imagem do Novo Mundo como o Éden terrestre. Sobre isso, passamos a tecer algumas considerações.

\section{OS MOVIMENTOS ILUSTRADOS E ROMÂNTICOS: NARRATIVAS EM DISPUTA}

Vamos agora exemplificar duas questões que vimos estudando. A primeira refere-se à multiplicidade de formas de ler a natureza, tanto em momentos históricos distintos como em uma mesma época. $\mathrm{O}$ segundo ponto diz respeito às rupturas que se processam na história. Nesta seção, mostraremos como se rompeu, no século XVIII, a associação do Novo Mundo com a idéia do Paraíso terrestre. Uma nova forma de ver, ler e narrar a natureza do continente americano surge.

As narrativas negativas sobre o Novo Mundo emergem com força através do movimento ilustrado do século XVIII. Conforme Roberto Ventura (1991) nos mostra, a "filosofia da Ilustração inverteu a visão paradisíaca da América, ao formar um novo discurso sobre o homem e a natureza americanos, marcado pela negatividade" (p. 22). Através das obras de pensadores como Georges-Louis Buffon, Cornelius De Pauw e Guillaume Raynal, marcou-se a inferioridade do ambiente do Novo Mundo e a fraqueza das formas de vida que o habitavam. Tais estudiosos eram adeptos do Classicismo - uma vertente artística e estética, associada ao chamado "Século das Luzes", ancorada na busca da transparência, da clarividência e da racionalidade das "coisas" do mundo. A natureza foi concebida pelos adeptos da Ilustração como uma exterioridade a ser apreendida pela razão. Em outras palavras, a natureza seria apreensível racionalmente e regida por leis. Se a razão era um atributo próprio aos sujeitos europeus (sobretudo homens e brancos), aos climas temperados e à civilização, somente ao lado da irracionalidade, da barbárie e da selvageria poderia estar o Novo Mundo e, conseqüentemente, a floresta e os sujeitos que viviam em um clima tropical.

Em contraposição a estas narrativas emergem, ainda no século XVIII, aquelas que se configuram a partir das premissas românticas edificadas por Rousseau, que afirmavam "a superioridade do homem natural e de seu equivalente histórico - o selvagem - sobre o civilizado 
europeu" (VentuRA, 1991, p. 23). Em oposição à Ilustração, o Romantismo dota a irracionalidade com uma força positiva. E mais, como argumenta Gerd Borheim (2002), segundo as premissas do movimento romântico do século XVIII, seria a partir de nossa interioridade que poderíamos "compreender [...] a natureza [como] ainda isenta da mácula de mão humana, estranha e anterior à cultura" (p. 81). Autores como o naturalista Alexander von Humboldt, sob inspiração romântica, invertem, no início do século XIX, "a imagem negativa da natureza tropical e do clima americano" (p. 27). O naturalista alemão é configurado como aquele que, além de romper com uma descrição negativa do Novo Mundo, uniu ciência e arte na constituição discursiva da natureza.

A luta pela imposição de significados travada entre a Ilustração e o Romantismo é entendida como fornecendo os argumentos que permearam a disputa entre a idealização e a desilusão do Novo Mundo no século XVIII e início do século XIX, tal como analisada no importante livro de Antonello Gerbi (1996). A partir da obra de Humboldt, o século XIX pôde assistir à emergência de narrativas que procuraram marcar a positividade dos territórios do Novo Mundo, processando uma ruptura tanto com a imagem do Paraíso como com a depreciação ilustrada. Porém, é preciso considerar que tanto para os naturalistas ilustrados do século XVIII como para os "discípulos" de Humboldt no século XIX (que uniram ciência e arte, sob inspiração romântica), a natureza passou a ser concebida como um objeto das Ciências Naturais.

Se nos séculos XV e XVI o encanto da viagem pelo Novo Mundo remetia à descrição do encantado e do maravilhoso, o encanto da viagem dos séculos XVIII e XIX estava na possibilidade de fortalecer uma ciência natural em consolidação.

Feitas estas considerações que marcam as disputas que se travam em torno das significações sobre o Novo Mundo, cabe agora uma indagação: podemos perceber rastros destas conformações atuando nas sociedades contemporâneas? Passamos a refletir a partir desta questão na seção seguinte.

\section{COMEÇANDO A PERGUNTAR SOBRE EDUCAÇÃo AMBIENTAL}

Como salientamos, no século XVIII emergiu, em contraposição ao movimento ilustrado, uma nova forma de percepção do mundo natural configurada como o fenômeno das "novas sensibilidades". Interessante 
apontar, como argumenta Carvalho (2001), que "essa cultura de valorização da natureza vai se reafirmar com o movimento romântico europeu do século XIX" (p. 43). Como destaca a autora, um conjunto de hábitos nesta direção já pode ser amplamente identificado na literatura e na pintura dos séculos XVIII e XIX, como, por exemplo, "manter em casa um pequeno jardim, criar animais domésticos, fazer passeios ao ar livre, piqueniques nos bosques" (p. 46), entre outros.

Não podemos associar permanências destas "novas sensibilidades" conformando, em parte pelo menos, nossas ações educativas contemporâneas? Por que na maioria das vezes escolhemos um lugar de natureza mais preservada para nossas práticas de educação ambiental? Como emerge este nosso desejo de quase sempre querer levar nossos alunos, quando pensamos em um trabalho de educação ambiental, para fora dos muros escolares, para locais como matas, bosques, parques, áreas de preservação etc.? Mesmo na escola, quando vamos propor um projeto de educação ambiental, não incorporamos, muitas vezes a esse, vivências usualmente consideradas mais aproximadas à natureza?

O chamado "mito moderno da natureza intocada" (DiEgues, 1996), atuante nas estratégias de delimitação de parques de proteção natural, é tributário dessas novas sensibilidades. O primeiro parque nacional, considerado área natural e selvagem, foi Yellowstone, nos Estados Unidos, criado em meados do século XIX. A urbanização acelerada, a expansão agrícola e a industrialização crescente colocavam em destaque discursos de valorização estética da natureza como uma fonte de bondade e beleza. $\mathrm{Na}$ contemporaneidade, assistimos a um intenso debate sobre as formas de proteger a natureza e os seres a ela ligados. De forma muito sintética, podemos dizer que alguns pesquisadores consideram importante manter os seres humanos afastados dessas áreas, enquanto outros defendem a idéia de que as populações humanas que historicamente já viviam nelas são responsáveis, inclusive, pela sua preservação e pela sua diversidade social e biológica. (Diegues, 2000).

Será que os seres humanos só podem ser vistos como destruidores do mundo natural? É possível generalizar a degradação ambiental do nosso tempo a toda e qualquer forma de vida humana? Seria também interessante pensarmos na preservação de culturas e modos de vida mais sintonizados com a natureza? Mas isso não faria com que grupos humanos não pudessem compartilhar, por exemplo, dos possíveis "ganhos" que as "novas" tecnologias nos possibilitam? Como podemos aliar a preservação 
cultural e ambiental com a necessária conexão global que se torna quase um imperativo dos nossos tempos?

Para finalizar essas considerações, vale lembrar que as "novas sensibilidades", como Carvalho (2001) salienta, se constituem como uma transformação cultural de longa duração, "que chega até os dias de hoje como uma das raízes histórico-culturais do ambientalismo contemporâneo" (p. 47). Será sobre a emergência desses movimentos sociais, sobretudo a partir dos anos 1970, que focaremos a seção seguinte, ressaltando que será a partir desses movimentos que a educação ambiental emergiria no cenário das sociedades no final do século XX.

\section{Os MOVIMENTOS ECOLÓGICOS E A CONTESTAÇÃO SOCIAL}

Discursos de proteção à natureza podem ser lidos em muitos momentos da história do Brasil. Em um importante livro que retrata a história ambiental do Brasil nos séculos XVIII e XIX, Pádua (2002) nos mostra como, por exemplo, José Bonifácio, um dos principais intelectuais atuantes no processo de independência do Brasil, já no início do século XIX preocupava-se intensamente com as práticas de desmatamento e de queimadas, alertando para a possível desertificação das terras e o dessecamento das águas.

Na década de 50 do século XX, também podemos identificar tais discursos, por exemplo, como nos mostrou Guimarães (1998), em inúmeros artigos jornalísticos escritos por Henrique Luis Roessler, que em 1955 fundou a União Protetora da Natureza (UPN), sediada no município de São Leopoldo, no Rio Grande do Sul.

Mesmo em contextos diferentes e por razões também diversas, podemos ver, através desses exemplos, que discursos de proteção à natureza estiveram circulando pelas sociedades em muitos momentos da história. Porém, será na década de 70 do século XX que emergirão movimentos sociais, chamados de ecológicos, que disseminarão de forma muito mais ampla as temáticas ambientais pelas sociedades. Como foi possível essa emergência? Quais idealizações estavam coladas a esses movimentos? Estas serão algumas das indagações que abordaremos a seguir.

Várias histórias sobre os movimentos ecológicos já nos foram contadas. Estes foram, sem dúvida, movimentos que se disseminaram a partir dos anos 1960 e 1970, por vários países do mundo. Não vamos detalhar todos os aspectos concernentes a essas histórias. Selecionamos 
duas questões para marcarmos como centrais sobre os movimentos ecológicos. Focamo-las para que possamos vislumbrar a importância que tais movimentos tiveram na emergência de um novo campo de estudos e práticas que paulatinamente, sobretudo nos anos 1990, consolidar-se-á como Educação Ambiental. O primeiro aspecto que ressaltaremos é a vinculação dos movimentos ecológicos com os ideários de contestação social que inundaram o cenário social mundial, ou seja, especialmente das sociedades ocidentais, já nos anos 1960. O segundo refere-se a vêlos como plurais e, muitas vezes, como aglutinadores de perspectivas e interesses muito diversos, embora sejam analisados geralmente como unitários e homogêneos. Iniciamos, então, focando a vinculação dos movimentos ecológicos com os ideários de contestação social.

A primeira fase do capitalismo industrial, marcado pelas máquinas a vapor e pelo carvão, era relativamente pouco expansiva sobre os territórios e as vidas humanas (embora essa possa ser vista como superior às sociedades notadamente agrícolas anteriores). Já a segunda fase petrolífera e elétrica disseminou-se fervorosamente, pois permitiu a produção industrial em larga escala, exigindo uma nova organização do trabalho e um consumo massivo de produtos. Esta nova conformação mundial de produção e consumo de materiais permitirá a proliferação de movimentos contestatórios que nos alertaram para os limites do crescimento industrial e populacional, entre outras bandeiras.

Dessa forma, argumentamos que as inspirações ideológicas dos movimentos ecológicos podem ser analisadas como vinculadas aos movimentos de contracultura dos anos 1960 (movimentos pacifistas, hippies, feministas, estudantis, entre outros). Tais movimentos estiveram radicalmente envolvidos na crítica das sociedades industriais e dos costumes racionalizados da vida moderna. Foram acentuadamente enfatizados os limites do progresso enredado à exploração capitalista, que era vista com uma dupla conotação, ou seja, como exploração tanto dos recursos naturais como também do trabalho humano. O crescimento tanto do consumo de matérias-primas como da própria população humana foram entendidos como desencadeadores de um colapso futuro das condições de vida no planeta. Esses discursos, divulgados amplamente pela contracultura ecológica, foram considerados promotores da idéia de catástrofe ambiental e como prognósticos de uma necessária inversão radical nos nossos estilos de vida e hábitos de consumo, sem a qual a vida no planeta estaria em perigo. Livros como Primavera silenciosa, de 
Rachel Carson, e Antes que a natureza morra, de Jean Dorst, tornaram-se marcos da contracultura ecológica.

Embora essa articulação dos movimentos ecológicos com outros movimentos contestatórios à época possa nos fazer pensar que eles sejam homogêneos, não será dessa forma que os configuraremos. Claramente há um componente que unificou os diferentes sujeitos que gravitaram em torno dos movimentos ecológicos: o ideário contestador dos modos de vida das sociedades capitalistas. Porém, muitos interesses e expectativas divergentes estiveram em jogo nesse processo. Em torno, por exemplo, da Associação Gaúcha de Proteção do Ambiente Natural (AGAPAN), criada em 1971, vincularam-se sujeitos, como nos mostrou Guimarães (1998), que participavam de associações naturalistas com o intuito de viverem mais próximos à natureza, professores universitários e cientistas de várias áreas, estudantes universitários e da escola secundária, profissionais das áreas da engenharia e da arquitetura, sujeitos filiados a diversas correntes partidárias como a Arena (frente política de sustentação dos governos militares) e do MDB (a frente que reunião as oposições).

Em resumo, queremos insistir que os movimentos ecológicos ao surgirem na esteira de um conjunto amplo de outros movimentos contestatórios inauguram, em relação aos discursos sobre a natureza de épocas anteriores, uma disseminada crítica global à sociedade industrial e aos estilos de vida dela derivados. Esse ideário, embora circulante pelos movimentos em seu conjunto, esteve longe de homogeneizá-los e circunscrevê-los a uma única direção. Os movimentos ecológicos aglutinaram um conjunto amplo de sujeitos com interesses e propósitos muito variados.

\section{A EMERGÊNCIA DA EDUCAÇ̃̃o AMBIENTAL NO BRASIL}

Será na esteira dos movimentos ecológicos dos anos 1970 que alguns princípios "educativos" começaram a singularizar-se como estreitamente vinculados ao campo ambiental. Embora não possamos falar, no início dos anos 1970, de uma Educação Ambiental, pois esta só começará a se consolidar nos anos 1980, podemos ver fortemente um "educativo" sendo articulado através das práticas dos militantes daqueles movimentos. Parece-nos importante destacar um trecho de um manifesto escrito por José Lutzenberger (1977), no qual podemos ler a centralidade que a educação vai assumindo, enquanto importante campo de luta contra a 
enorme crise ambiental pela qual passávamos, conforme os militantes nos alertavam. Nas palavras de Lutzenberger (1997):

Fundamentalmente, a solução dos problemas ambientais está na educação. Mas a educação é um processo lento, demasiado lento para conter ainda a avalanche que se aproxima do estrondo. Já não podemos esperar que a próxima geração indique o novo rumo e repare os estragos. Se nada fizermos hoje, não lhes deixaremos chance para tanto. Que adianta ensinar aos jovens o amor à Natureza se, daqui a dez ou vinte anos, quando a eles couber o poder de decisão, não mais existir natureza para salvar. Para que ainda tenha sentido a educação da juventude, devemos fixar já os novos caminhos, devemos começar logo a reparar o que pode ser reparado, devemos evitar a continuação e o incremento dos estragos e devemos iniciar hoje os processos que só frutificarão em longo prazo. (p. 60)

Como podemos ler no trecho acima, a importância da educação para as lutas ambientais estava marcada desde aqueles tempos de emergência dos movimentos ecológicos. A partir daquele momento, passou a ser necessário agir imediatamente. Os movimentos ocupavam as ruas, as vozes ecoavam em jornais, revistas, rádios e programas televisivos. Os movimentos procuravam fazer barulho, se mostrarem grandes e fortes, inibidores das práticas pelas quais lutavam e condenavam. Essas eram ações imediatas e que deveriam estar articuladas cotidianamente. A educação, embora vista como fundamental, atendia a um tempo não imediato, pois seus frutos só seriam colhidos futuramente. Nada substituía as lutas que deveriam urgentemente tomar as ruas. De qualquer forma, sua importância estava marcada nesse importante "Manifesto". E, mais, as próprias estratégias de luta podem ser vistas como "educativas", como práticas de subjetivação, ou seja, como formadoras dos sujeitos.

Alguns princípios "educativos" que deveriam nortear a formação das futuras gerações mostravam-se imperativos naqueles anos: era necessária uma mudança de atitudes, um reexame dos valores e uma redefinição do progresso e do desenvolvimento.

Nesta direção, podemos dizer que princípios "educativos" atrelados ao campo ambiental emergem, de forma mais visível e disseminada, a partir dos anos 1970. E eles articulam-se, naquele momento, como ação política de transformação dos valores e das atitudes dos sujeitos. Com isso, podemos vislumbrar que um educativo-ambiental não começa a delinear-se no cenário das sociedades, somente, por iniciativas oficiais 
materializadas em conferências e documentos internacionais. Queremos marcar fortemente a emergência de princípios educativos já nos movimentos ecológicos contestatórios.

Em resumo, queremos salientar que será nesse contexto de mobilizações e de contestações sociais que um educativo-ambiental começará a se configurar na cena social.

Contudo, será somente nos anos 1980 que a Educação Ambiental emergirá como um campo de saberes e práticas. Porém, é preciso considerar que serão os anos 1990 os responsáveis pela sua consolidação e crescente institucionalização. A Conferência das Nações Unidas para o Meio Ambiente e Desenvolvimento, no Rio de Janeiro, em 1992, é considerada um marco do início da sua expansão. Como nos mostra Marcos Reigota (1998), desde meados dos anos 1990 proliferaram consideravelmente as teses de doutorado, as dissertações de mestrado, as monografias, bem como os livros e artigos em revistas científicas sobre Educação Ambiental. Ampliou-se, inclusive, o número de cursos de formação na área oferecidos por empresas, órgãos governamentais, universidades e organizações não-governamentais. Os primeiros Fóruns Nacionais de Educação Ambiental ocorreram também nessa década. Pode-se dizer então que todos esses processos vão, ao mesmo tempo, fornecendo maior visibilidade e consolidando uma educação que agora passa também a ser qualificada como ambiental.

Longe de ser esse um processo pacífico e unitário, como se facilmente pudéssemos definir a Educação Ambiental e, mais, ainda, enxergar os sujeitos a ela atrelados como compartilhando idéias e concepções em uma mesma direção, o campo vai consolidando-se e configurando-se como contestado, ou seja, como conformado por diferentes concepções políticas, perspectivas teóricas, epistemologias, enfim, um campo aberto em suas fronteiras.

Que possamos nos instaurar nas fissuras da Educação Ambiental, pensando políticas que possam nos remeter a construção de coletivos de naturezas e culturas não permeados, somente e derradeiramente, pelas premissas de um mercado volátil e incisivo sobre nossas existências.

\section{ABSTRACT}

This paper briefly presents ways in which nature has been historically signified in culture. To do so, the text first focuses on two different historical moments and presents some of the arguments involving the meanings of nature occurring 
in societies at those times. The second part of the paper focuses more closely on the emergence of challenging ecological movements in the 1970s and the later emergence of a challenging field of knowledge and practice: environmental education. In all these different historical moments, the centrality of culture in relation to the way nature is read is highlighted.

Keywords: Cultural studies. Environmental education. Environmental history. Ecological movements.

\section{NOTA}

1. Uma versão preliminar deste artigo foi apresentada no Grupo de Trabalho de Educação Ambiental, na 29 ${ }^{\text {a }}$ Reunião Anual da Associação Nacional de Pesquisa e Pós-Graduação em Educação (ANPED).

\section{REFERÊNCIAS}

ARNOLD, D. La naturaleza como problema histórico: el medio, la cultura y la expansión de Europa. México: Fondo de Cultura Econômica, 2001.

BORHEIM, G. A filosofia do romantismo. In: GUINSBURG, J. O romantismo. São Paulo: Perspectiva, 2002.

CARVALHO, I. A invenção ecológica: narrativas e trajetórias da educação ambiental no Brasil. Porto Alegre: UFRGS, 2001.

DIEGUES, A. C. O mito moderno da natureza intocada. São Paulo: Hucitec, 1996.

. Etnoconservação da natureza: enfoques alternativos. In: (Org.).

Etnoconservação: novos rumos para a proteção da natureza nos trópicos. São Paulo: Hucitec, Nupaub-USP, 2000.

GERBI, A. O Novo Mundo: história de uma polêmica (1750-1900). São Paulo: Companhia das Letras, 1996.

GUIMARÃES, L. B. O educativo nas ações, lutas e movimentos de defesa ambiental: uma história de descontinuidades. 1998. Dissertação (Mestrado em Educação) - Faculdade de Educação da Universidade Federal do Rio Grande do Sul.

HOLANDA, S. B. de. Visão do paraíso: os motivos edênicos no descobrimento e colonização do Brasil. São Paulo: Brasiliense, 1996.

LEITE, J. R. T. Viajantes do imaginário: a América vista da Europa, séc. XVXVII. Revista USP, São Paulo: (30): 32-45, jun./ago., 1996. 
LUTZENBERGER, J. Fim do futuro? Manifesto ecológico brasileiro. Porto Alegre: Movimento, UFRGS, 1977.

PÁDUA, J. A. Um sopro de destruição: pensamento político e crítica ambiental no Brasil escravista (1786-1888). Rio de Janeiro: Jorge Zahar, 2002.

REIGOTA, M. Educação Ambiental: fragmentos de sua história no Brasil. In: BARCELOS, V.; NOAL, F.; REIGOTA, M. (Orgs.). Tendências da educação ambiental brasileira. Santa Cruz do Sul, SC: Edunisc, 1998.

VENTURA, R. Estilo tropical: história cultural e polêmicas literárias no Brasil. São Paulo: Companhia das Letras, 1991.

ZILBERMAN, R. A terra em que nasceste: imagens do Brasil na literatura. Porto Alegre: UFRGS, 1994.

WORTMANN, M. L. C. Da inexistência de um discurso unitário para falar da natureza. In: SCHMIDT, S. A educação em tempos de globalização. Rio de Janeiro: DP\&A, 2001.

; BRAUN, M. C. A produção de representações culturais de natureza na ambientação de um grupo étnico no Sul do Brasil. In: NOAL, F.; BARCELOS, V. (Orgs.). Educação ambiental e cidadania: cenários brasileiros. Santa Cruz do Sul: Edunisc, 2003. 